\title{
CORRIGENDA
}

\section{Corrigendum: Shifting HIFs in osteoarthritis}

Matthew Husa, Ru Liu-Bryan \& Robert Terkeltaub

Nat. Med. 15, 641-644 (2010), published online 4 June 2010; corrected online 7 July 2010

In the version of this article initially published online, a reference was missing and a label was misplaced within the figure. The errors have been corrected for the PDF and HTML versions of this article.

\section{Corrigendum: Autophagy enhances the efficacy of BCG vaccine by increasing peptide presentation in mouse dendritic cells}

Chinnaswamy Jagannath, Devin R Lindsey, Subramanian Dhandayuthapani, Yi Xu, Robert L Hunter Jr \& N Tony Eissa Nat. Med. 15, 267-276 (2009), published online 1 March 2009; corrected online 7 July 2010

In the version of this article initially published online, Figure $1 \mathrm{~b}$ was a copy of Figure $4 \mathrm{~b}$, and Figure $3 \mathrm{~d}$ did not show all the correct bands. Both figures have been corrected for the PDF and HTML versions of this article. The legends and interpretation of the data remain the same. 